ORIGINAL ARTICLE

\title{
Comparison of the Number of Attempts in Creating Pneumoperitoneum for Laparoscopic Cholecystectomy Using Direct Trocar Versus Veress Needle Insertion
}

\author{
KAMRAN HAMID ${ }^{1}$, SHABBIR AHMAD ${ }^{2}$, FAISAL SHABBIR ${ }^{3}$, AMER LATIF ${ }^{4}$, SHAHZAD ASHRAF ${ }^{5}$, MUHAMMAD FAHEEM \\ ANWER ${ }^{6}$, MUHAMMAD ASIM RANA ${ }^{7}$, MUHAMMAD MANSOOR HAFEEZ ${ }^{8}$ \\ ${ }^{1}$ Senior Registrar Department of Surgery, Islam Medical College, Sialkot, Pakistan \\ ${ }^{2}$ Assistant Professor, Department of Surgery, Islam Medical College, Sialkot, Pakistan \\ ${ }^{3}$ Associate professor, Department of Surgery, Khawaja Muhammad Safdar Medical College, Sialkot \\ ${ }^{4}$ Associate Professor, Department of HPB Surgery, Shaikh Zayed Hospital, Lahore \\ ${ }^{5}$ Consultant, Department of General Surgery, Bahria International Hospital, Lahore \\ ${ }^{6}$ Associate professor, department of surgery, CMH Lahore medical college \\ ${ }^{7}$ Head Department of Critical Care, Bahria International Hospital, Lahore \\ ${ }^{8}$ Director Research \& Development, Expert Doctor Private Limited, Lahore, Pakistan \\ Correspondence to: Dr. Muhammad Mansoor Hafeez, E-mail: mansoorhafeez140@gmail.com Cell 03214231613
}

\begin{abstract}
Aim: To compare the number of attempts at creating pneumoperitoneum for laparoscopic cholecystectomy using direct trocar versus veress needle insertion techniques.

Design: Randomized controlled trial

Place and Duration of Study: Department of Surgery, Allama Iqbal Memorial Hospital Sialkot and Govt. Sardar Begum Teaching Hospital, Sialkot from 27 ${ }^{\text {th }}$ September 2017 to $26^{\text {th }}$ September 2020.

Methodology: Six hundred and eight patients of both male and female patients, having uncomplicated cholelithiasis were selected. All participants were randomized into two equal groups, Group A (direct trocarlnsertion) and the Group B (veress needle insertion). All trocars and veress needle used were disposable, with a safety shield. All procedures were carried out by the single experienced surgeons and his team. Data was noted, regarding age, sex, body mass index (BMI) and the number of attempts to create the successful pneumoperitoneum.

Results: The number of attempts to create successful pneumoperitoneum in DTI group was significantly feweras compared to $\mathrm{VNI}$ group $(p=0.026)$ but we found no statisticallysignificant difference between age, gender, and body mass index.

Conclusion: The direct trocar insertion is a safe alternative to veress needle insertion in laparoscopic cholecystectomy because it requires fewernumber of attempts for successful creation of pneumoperitoneum as compared to the veress needle.
\end{abstract}

Key words: Laparoscopic cholecystectomy, Veress needle insertion, Direct trocar insertion, Pneumoperitoneum

\section{INTRODUCTION}

Entry of surgical instruments through a small hole or incision is always a big challenge in laparoscopic surgery. More than $50 \%$ of major complications such as gastrointestinal or large vessel injuries reportedbefore the start of the any laparoscopic surgery. ${ }^{1}$ Laparoscopic cholecystectomy is most performed procedure after the 1980s and it has replaced classic cholecystectomy.Development of video cameras and other auxiliary instruments led to rapid developments in laparoscopy from a diagnostic tool in a specialized field in surgery for a variety of surgical procedures. ${ }^{2}$

To reduce the chances of trocar insertion related injuries, various techniques, instruments, and different approaches have been introduced and tried during the last few decades. These include the Veress pneumoperitoneum-trocar for "classic" or closed entry, the open (Hasson) technique, direct trocar insertion without prior pneumoperitoneum, use of shielded disposable trocars. ${ }^{3}$

Veress needle, as compared to the optical trocar, equipped with a spring-loaded obturator that is used in laparoscopic surgery toaccess the peritoneal cavity before insufflation of the abdominal cavity. Use of each abovementioned instrument depends on surgeon's preference that mostly based on surgeons training and easy availability of instruments. Hasson technique has been safest when comparison was made between open versus closed entry to establish pneumoperitoneum. ${ }^{4}$

A Canadian study conducted by the four hundred and seven gynaecologists and obstetricians, in which almost always pneumoperitoneum was created before putting primary trocar in place. It was found that, few of them have been victims of vascularor organdamage caused by the insertion of the Veress needle. $25.6 \%$ and $15.0 \%$ suffered damage to vessels or organs caused by primary and secondary trocars, respectively. So, it can be included the number of attempts by veress may be a factor in the increase in the number of complications. This study also showed that that on the first attempt, the complication rate ranged from $0.8 \%$ to $16 \%$ on the second attempt, from $16.31 \%$ to $37.5 \%$ on more than three attempts, from $86 \%$ to $100 \% .^{2}$

Dingfelder was the first to utilize and publish an article in 1978 related to thedirect entry into the abdomen with a trocar. It is a $10 \mathrm{~mm}$ diameter, a sharp metal device consisting of an obturator, a cannulaand a seal.The trocar acts as a portal for the later installation of other instruments,such as grippers, scissors, staplers, etc.The insertion of the trocar was superior to the insertion of the 
Veress needle, since it was faster and prevented the following complications:defective pneumoperitoneum, peritoneal or intestinal insufflationor more dangerous $\mathrm{CO} 2$ embolism. ${ }^{5}$ The direct input method is more rapid than any other input method. ${ }^{6}$

However, it is also noted to have a different out outcome owning to have risk factors such as diabetes. ${ }^{7}$ Direct trocar insertion and open technique when compared with Veress needle use have resulted in fewer complications like wound infection, omental injury, and port site bleeding. ${ }^{8}$ Previous studies conducted in Pakistan have comparable safety and efficacy of open versus blind techniques, but no local study has compared the mean number of attempts to create pneumoperitoneum between two blind procedures (direct trocar and Veress needle). A study conducted to compare direct trocar insertion has created pneumoperitoneum in $92.7 \%$ cases in first successful attempt, second successful attempt in 6.3\% cases and third successful attempt in $1.1 \%$ cases and maximum of three attempts after which open technique was used. ${ }^{9}$ Meta-analysis conducted by Jiang et $\mathrm{al}^{10}$ reported more than 2 (2.99 [2.11-4.23]) attempts of Veress needle when compared with Hasson's cannula.

Rationale of the study is to establish whether a direct trocar entry or Veress needle isthe safest method for creation of pneumoperitoneum with the least number of attempts, as it is a common perception that an increasing number of attemptstend to increase the rate of complications, hence decrease safety of this minimal invasive procedure. ${ }^{11}$

\section{MATERIALS AND METHODS}

This current analysis was done from $27^{\text {th }}$ September2017 to $26^{\text {th }}$ September 2020, at surgical department of Khawaja Safdar Medical College, Government Sardar Begum Teaching Hospital Sialkot, and Allama lqbal Memorial Hospital. A total of six hundred and eight patients of plannedlaparoscopic cholecystectomy was included after taking the written consent.Patients aged 30 to 75, both male and female, having symptomatic uncomplicated cholelithiasis were included. Patients with historyofadvanced gastrointestinal or gynaecological procedure, chronic liver disease detected on ultrasound abdomen and with coexisting deranged liver function tests (bilirubin $>1.1$, AST,ALT> 45IU, serum albumin <3.3), ischaemic heart disease(evident on ECGinform of Qwaves), para-umbilical hernia, previous laparotomy were excluded.All patients underwent a detailed history, followed by a comprehensive routine evaluation and basic biochemical analysis.All patients were subjected to a detailed history, followed by complete routine examination and baseline investigations. Patients were divided into two groups, Group A contained 304 patients in which the pneumoperitoneum were created through direct trocar insertion (DTI) and Group B had the same number of ageand sex matched patients undergone veress needle insertion (VNI). Patients were randomly divided via lottery method while undergoing laparoscopic procedures to establish pneumoperitoneum with Veress needle or Direct Trocarentry.Each selected casewas performed by experienced General Surgeon.In technique of Direct Trocar Insertion,the positioning of the patient is the same as in
Veress needle insertion,thatis positioned in supine with a 20- to 30-degree Trendelenburg tilt. The data collected was analysed with SPSS software version 22 . The chi-square test after stratification was applied with ap-value of less than 0.05 determined to be statistically significant.

\section{RESULTS}

The mean age of patients in the present studywas $47.99 \pm 11.01$ years. Mean body mass index (BMI) of study patients was $26.18 \pm 3.88 \mathrm{Kg} / \mathrm{m}^{2}$ (Table 1). There were 211 (34.70\%) male patients and 397 (65.30\%) female patients (Fig. 1).

Comparison of number of attempts wasmade indirect trocar insertion (DTI) and veress needle insertion (VNI) groups. In DTI group, pneumoperitoneum was created successfully in the firstattempt in278 $(91.4 \%)$ patients, in2 ${ }^{\text {nd }}$ attemptin20 $(6.6 \%)$ patients andin $3^{\text {rd }}$ attemptin6 $(2.0 \%)$ patients, whileinVNI group, pneumoperitoneum was successful at firstattemptin $256(84.2 \%)$ patients,in2 ${ }^{\text {nd }}$ attemptin38 (12.5\%) patients andin $3^{\text {rd }}$ attemptin10 $(3.3 \%)$ patients [ $p$-value 0.02] (Table 2).

In patients having age 30-45 years, pneumoperitoneum was successful in 114 patients in first attempt and in 7 patientsin2 $2^{\text {ndattempt. While it was }}$ successful in the first attempt in 110patients and in

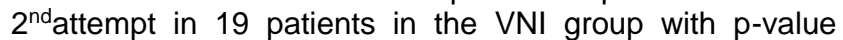
0.06 . Table 3 shows a statistically significant difference for the 46-60 age groups, but no statistically significant difference for the 61-75 age group(Table3).

There was no difference found in male and female between two groups (Table 4). Comparison of BMI showed no statistically significant difference between two groups (Table 5).

Table 1: Descriptive statistic of age and BMI of patients

\begin{tabular}{|l|l|}
\hline Variable & Mean \pm SD \\
\hline Age $($ Years $)$ & $47.99 \pm 11.01$ \\
\hline BMI $\left(\mathrm{kg} / \mathrm{m}^{2}\right)$ & $26.18 \pm 3.88$ \\
\hline
\end{tabular}

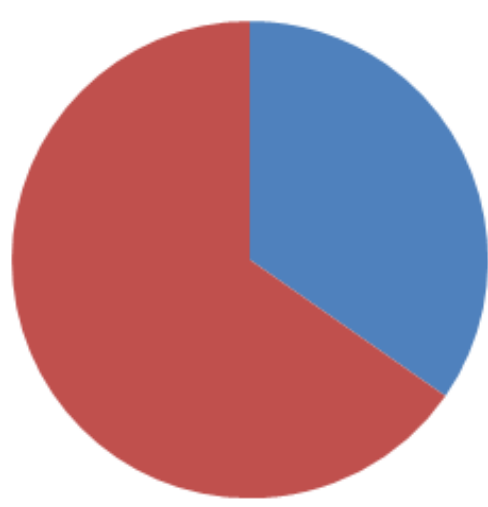

Male - Female

Fig. 1: Frequency of genders

Table 2: Comparison of number of attempts between two groups

\begin{tabular}{|l|l|l|l|}
\hline $\begin{array}{l}\text { No. of } \\
\text { Attempts }\end{array}$ & $\begin{array}{l}\text { Direct Trocar } \\
\text { Insertion }\end{array}$ & $\begin{array}{l}\text { Veress Needle } \\
\text { Insertion }\end{array}$ & P-value \\
\cline { 1 - 3 } $1^{\text {st }}$ & $278(91.4 \%)$ & $256(84.2 \%)$ & \multirow{2}{*}{0.024} \\
\hline $2^{\text {nd }}$ & $20(6.6 \%)$ & $38(12.5 \%)$ & \\
\hline $3^{\text {rd }}$ & $6(2.0 \%)$ & $10(3.3 \%)$ & \\
\hline
\end{tabular}


Table 3: Comparison of age, according to determinethe effect on the number of attempts between the groups

\begin{tabular}{|c|c|c|c|c|}
\hline Age (years) & No. of attempts & DTI & VNI & $\mathrm{P}$ value \\
\hline \multirow{3}{*}{$30-45$} & $1^{\text {st }}$ & 114 & 110 & \multirow{3}{*}{$0.06^{*}$} \\
\hline & $2^{\text {nd }}$ & 7 & 19 & \\
\hline & $3^{\text {rd }}$ & 3 & 3 & \\
\hline \multirow{3}{*}{46.60} & $1^{\text {st }}$ & 133 & 131 & \multirow{3}{*}{0.04} \\
\hline & $2^{\text {nd }}$ & 4 & 10 & \\
\hline & $3^{\text {rd }}$ & 1 & 7 & \\
\hline \multirow{3}{*}{$61-75$} & $1^{\text {st }}$ & 31 & 15 & \multirow{3}{*}{$0.15^{*}$} \\
\hline & $2^{\text {nd }}$ & 9 & 9 & \\
\hline & $3^{\text {rd }}$ & 2 & - & \\
\hline
\end{tabular}

${ }^{*}$ Not significant

Table 4: Comparison of gender to determine the effect on the number of attempts between the groups

\begin{tabular}{|l|l|l|l|l|}
\hline Gender & No. of attempts & DTI & VNI & P value \\
\hline \multirow{3}{*}{ Male } & $1^{\text {st }}$ & 103 & 87 & \multirow{3}{*}{$0.31^{*}$} \\
\cline { 2 - 4 } & $2^{\text {nd }}$ & 7 & 10 & \\
\cline { 2 - 4 } & $3^{\text {rd }}$ & 1 & 3 & \\
\hline \multirow{3}{*}{ Female } & $1^{\text {st }}$ & 175 & 169 & \multirow{3}{*}{$0.06^{*}$} \\
\cline { 2 - 4 } & $2^{\text {nd }}$ & 13 & 28 & \\
\cline { 2 - 4 } & $3^{\text {rd }}$ & 5 & 7 & \\
\hline
\end{tabular}

${ }^{*}$ Not significant

Table 5: Comparison of body mass index to determine the effect on the number of attempts between the groups

\begin{tabular}{|l|l|l|l|l|}
\hline BMI $\left(\mathrm{kg} / \mathrm{m}^{2}\right)$ & No. of attempts & DTI & VNI & P value \\
\hline \multirow{3}{*}{$<24.99$} & $1^{\text {st }}$ & 112 & 106 & \\
\cline { 2 - 4 } & $2^{\text {nd }}$ & 8 & 16 & \multirow{3}{*}{$0.25^{*}$} \\
\cline { 2 - 4 } & $3^{\text {rd }}$ & 3 & 3 & \\
\hline \multirow{3}{*}{$25-29.99$} & $1^{\text {st }}$ & 130 & 119 & \multirow{3}{*}{$0.16^{*}$} \\
\cline { 2 - 4 } & $2^{\text {nd }}$ & 9 & 16 & \\
\cline { 2 - 4 } & $3^{\text {rd }}$ & 2 & 5 & \\
\hline \multirow{3}{*}{$>30$} & $1^{\text {st }}$ & 36 & 31 & \multirow{3}{*}{$0.42^{*}$} \\
\cline { 2 - 4 } & $2^{\text {nd }}$ & 3 & 6 & \\
\cline { 2 - 4 } & $3^{\text {rd }}$ & 1 & 2 & \\
\hline
\end{tabular}

${ }^{*}$ Not significant

\section{DISCUSSION}

Over the past two decades, swift development has turned laparoscopic surgery into a well-established procedure. Because, laparoscopy is comparatively a new technique, it is still controversial particularly concerning the safest approach for the establishment of pneumoperitoneum. ${ }^{12}$ The peritoneal cavity can be reached by means of a mini-laparotomy or the insertion of a laparoscopic trocaror a Hasson trocar. It is also possible to blind insert an optical trocarin the peritoneal cavity or a Veress needle can be inserted across the abdominal midline, or a trocarinserted directly without creating pneumoperitoneum. The latter is the method most often used. ${ }^{13}$

As direct visualization with the laparoscope precludes above mentioned complication, in the present study, we compared the number of attempts for successful creation of pneumoperitoneumin DTI group and VNI group of patients. In DTI group, pneumoperitoneum was created successfully in the first attemptin278 $(91.4 \%)$ patients, in $2^{\text {nd }}$ attempt in $20(6.6 \%)$ patients and in $3^{\text {rd }}$ attemptin6 $(2.0 \%)$ patients. While in VNI group, pneumoperitoneum was successful atfirst attemptin 256 (84.2\%) patients,in2 ${ }^{\text {nd }}$ attemptin38 (12.5\%) patients andin3 ${ }^{\text {rd }}$ attemptin10 (3.3\%) patients. In a study conducted by Ertugrul et al. Pneumoperitoneum was created successfully in first attemptin74.3\% patients and in $2^{\text {nd }}$ attemptin $15.6 \%$ patients in DTI group versus in $54.76 \%$ patients in first attempt andin30.95\% patients in second attempt in VNI group. The main difference in our study and in this study, due to the reason that these authors only included morbidly obese patients in their study and access is difficult in obese patients. ${ }^{11}$ Agrestaetal ${ }^{14}$ found a success rate of $100 \%$ for creating pneumoperitoneumin DTI andin98.7\% patients in the VNI group while Borgata etal ${ }^{15}$ reported a peritoneal success rate in first attempt in $92.2 \%$ patients in DTI group andin78.2\% patients in VNI group. The results of our study are comparable to the results of these studies. Although simple, the VNI method is not fool proof. They showed that tactile "pops" that indicate various strata of penetration are often illusions. The different tests and controls that assess needle placement are unreliable and sometimes deceptive. The direct insertion of a trocar is based more on visual confirmation, skill and knowledge of the anatomy and dynamics of the abdominal wall than on secondary tests which are not always reliable. Less instrumentation eventually results in reduced costs, and all the others being equal, less reliability.

The Society of Obstetricians and Gynaecologists of Canada recommended that the direct insertion of the trocarbe regarded as a safe alternative to the Veress needle technique. Among studies conducted in Pakistan a similar study comparing DTI insertion and complications on 200 patients by Tariq et al ${ }^{14}$ reports entry first attemptin176 cases $(92.6 \%)$, in second attemptin 12 cases $(6.3 \%)$, and in third attemptin2 cases $(1.1 \%)$ These results are like those in our study but there is randomization and comparison with other methods of entry. A study conducted at Akhtar Saeed Medical College Surgery department enrolled 30 patients each in DTI and VNI were allocated, and complication rates of both groups were studied. The study reported $100 \%$ creation of pneumoperitoneum in both groups, These results due to small sample size at best are unreliable.

\section{CONCLUSION}

Direct trocar insertion (DTI) is a safer alternative to veress needle insertion (VNI) in laparoscopic cholecystectomy. It requires fewer numbers of attempts for successful creation of pneumoperitoneum as compared to the veress needle.

\section{REFERENCES}

1. Jansen FW, Kapiteyn K, Trimbos-Kemper T, Hermans J, Trimbos JB. Complications of laparoscopy: a prospective multicentre observational study. BJOG 1997;104(5):595-600.

2. Vilos GA, Ternamian A, Dempster J, Laberge PY, Vilos G, Lefebvre G, et al. Laparoscopic entry: a review of techniques, technologies, and complications. J Obstet Gynaecol Canada 2007;29(5):433-47.

3. Nevler A, Har-Zahav G, Rosin D, Gutman M. Safer trocar insertion for closed laparoscopic access: ex vivo assessment of an improved Veress needle. Surg Endoscopy 2016;30(2):779-82.

4. Shayani-Nasab H, Amir-Zargar MA, Mousavi-Bahar $\mathrm{SH}$, Kashkouli Al, Ghorban-Poor M, Farimani M, et al. Complications of entry using direct trocar and/or veress needle compared with modified open approach entry in laparoscopy: six-year experience. Urol J 2013; 10(2):861-5.

5. Dingfelder J. Direct laparoscope trocar insertion without prior pneumoperitoneum. J Reprod Med 1978;21(1):45-7. 
6. Godara R, Bansal A, Verma S, Yadav S, Verma N, Gupta S, et al. Direct trocar insertion without the pneumoperitoneum in laparoscopic surgery-ls this a safe technique? Hellenic JSurg2015;87(5):415-8.

7. Chudhary HR, Amin A, Malik MH, Hafeez MM, Rana MA, Malik A. Risk assessment of non-conventional contributory factors in onset of diabetes mellitus type II. Biological ClinSciResJ2020;2020(1): e036-.

8. Angioli R, Terranova C, Nardone CDC, Cafà EV, Damiani $P$, Portuesi R, et al. A comparison of three different entry techniques in gynecological laparoscopic surgery: a randomized prospective trial. EurJObstetGynecolReprodBiol2013; 171(2):339-42.

9. Tariq M, Ahmed R, Rehman S, Sajjad M. Comparison of direct trocar insertion with other techniques for laparoscopy. JCPSP 2016;26(11):917-9.

10. Cakir T, Tuney D, Esmaeilzadem S, Aktan AO. Safe veress needle insertion. JHepatobiliaryPancreatic Surg2006;13(3):225-7.
11. Channa GA, Siddiqui AJ, Zafar SN. Open versus closed method of establishing pneumoperitoneum for laparoscopic cholecystectomy. JCPSP 2009;19(9):557-60.

12. Chotai NR, Choksi B, Damor S, Bhedi A. Intraperitoneal access by closed method (veress needle) versus open (Hasson's) method in laparoscopic surgery to create pneumoperitoneum. IntSurgJ2017;4(8):2786-90.

13. Toro A, Mannino M, Cappello G, Di Stefano A, Di Carlo I. Comparison of two entry methods for laparoscopic port entry: technical point of view. Diagnostic Therapy Endoscopy 2012;2012.

14. Choudhry ZA, Iqbal MS, Latif M, Hamid K. Comparison of direct trocar versus veress needle insertion in creation of pneumoperitoneum in patients undergoing laparoscopic cholecystectomy. APMC2019;13(2):126-9.

15. Johansson I, Lynøe N. Medicine \& philosophy: De Gruyter; 2013.

16. Agresta F, Mazzarolo G, Bedin N. Direct trocar insertion for laparoscopy. JSLS2012;16(2):255. 